who develop frank myeloma show an exponential increase in the serum content of paraprotein. In doubtful cases, monitoring the concentration of the paraprotein in the serum is the most useful indicator of the likely outcome, and the urine should be checked regularly for Bence Jones proteinuria. In order not to cause undue anxiety to patients the follow-up should be arranged yearly when the outcome seems likely to be benign and more often-perhaps every three months-when the likelihood is malignant disease.

Paraproteinaemia has been said to be associated with liver disease, gut disease, and carcinoma. Nevertheless, in Hobbs's study $^{2}$ of 368 patients with liver disease repeated protein electrophoresis found only three with paraprotein and among 326 patients with gut disease only one had a paraprotein. Neither of these proportions exceeds the expected natural incidence. In the same way, the $2 \%$ of 3000 patients with carcinoma found to have paraproteinaemia are no higher a proportion than would be expected in persons of that age.

Does finding two or more paraproteins have any more significance than the finding of a single band? Gore recently examined ${ }^{7}$ reports from a protein reference centre, and found that $11 \%$ of the patients had multiband paraproteinaemia. The finding of $60 \%$ of these with malignant paraproteinaemia was comparable with the incidence of monoclonal malignant paraproteinaemia reported from other laboratories. At present there seems no evidence that multiband myeloma has any worse prognosis than myeloma associated with a single paraprotein.

${ }^{1}$ Axelsson U, Hällén J. A population study on monoclonal gammapathy Acta Med Scand 1972;191:111-3.

2 Hobbs JR. Immunoglobulins in clinical chemistry. Adv Clin Chem 1971 ;14:218-317.

${ }^{3}$ Conklin R, Alexanian R. Clinical classification of plasma cell myeloma. Arch Intern Med 1975;135:139-43.

${ }^{4}$ Zawadzki ZA, Edwards GA. In: Schwartz RS, ed. Progress in Clinical Immunology. New York: Grune and Stratton, 1972;1:105.

${ }^{5}$ Hobbs JR. Monitoring immunocytoma. Minerva Med 1978;69:2499-506.

${ }^{6}$ Hobbs JR. Paraproteinaemia. Proc R Soc Med 1969;62:773-6.

7 Gore ME, Riches PG, Kohn J. Identification of the paraprotein and clinical significance of more than one paraprotein in serum of 56 patients. F Clin Pathol 1979;32:313-7.

\section{MDs or PhDs in medical research?}

Hard on the heels of the generalist versus specialist debate ${ }^{1}$ come warnings of another crisis in medical manpower in the United States. During the last decade there has been such a striking decline in the number of medically qualified research workers that JB Wyngaarden ${ }^{2}$ entitled his recent presidential address to the American College of Physicians "The clinical investigator as an endangered species." Between 1968 and 1973 the number of trainee awards given to medical men by the National Institutes of Health remained roughly constant at around 3000 , but since then there has been a precipitate drop to less than half that number. In part this has been due to a decision to discontinue awards to clinical trainees, but there had already been an apparent fall in those awards given solely for training in research. In contrast, awards to those holding $\mathrm{PhDs}$ have steadily risen. Another example of the decline is the scheme for young investigators, which began in 1971, when most of the recipients were clinicians; in the last three years they have been overtaken by scientists. Awards to principal investigators with MDs have fallen from $44 \%$ of the total in 1966 to $23.5 \%$ in 1977 , while awards to those with PhDs have risen from just under $50 \%$ to around $70 \%$. During this time the number of applications by medically qualified workers has remained constant while those from scientists have doubled. Success rates are similar, so that the increasing gap seems to be due to a failure of the pool of medical scientists to grow at the same rate as that of those with PhDs.

The numbers of medical school graduates and of full-time faculty has doubled in the last decade, yet the number of doctors engaged in research has fallen to half. The reasons for this decline are complex. Nowadays medical students are influenced by greater public emphasis on primary care and general dissatisfaction with high technology medicine. They are also much less exposed to laboratory work, which used to be one of the best features of American medical education. In the clinical years hospital medicine is attractive and exciting, with its emphasis on the short-term, expedient gathering of information by what has been called the "sponge mode."3 Furthermore, the specialty-certifying boards have changed their regulations to put greater emphasis on clinical experience. While doctors used to be able to start doing research after two years, and this counted towards training, the young graduate must now wait four years, by which time he may be in a position to make a lot of money out of practising his specialty. Senior researchers complain about the uncertainties of financial support, and about the amount of time they have to spend applying for grants and complying with regulations. Federal grants, in particular, have been subject to considerable government interference over the years, including definitions of areas of "need" and a payback penalty for clinicians (but not for those with $\mathrm{PhDs}$ ) who do not continue in approved health care services. Against that background the fact that some 500 of the postdoctoral awards for 1977 in the clinical sciences were not taken up is not surprising, now that nearly 500 others were filled by PhDs. Yet the need for sufficient clinical investigators to accomplish the long-term aims of medicine is surely not in doubt. The United States has enough high quality doctors and, even in these stringent days, the money to pay a decent wage without strings.

There are signs of a drift away from clinical research in Britain, too, ${ }^{4}$ where it still may be less difficult to get the necessary funds than to find enthusiastic young men and women. No doubt the economic rewards of medical practice, especially payments for overtime in hospital practice which may occasionally double a salary, act as a deterrent here as well. The number of British doctors with a bent for clinical research is never likely to be large, so we cannot afford to ignore their special needs.

1 Anon. The physicians' dilemma. Br Med f 1979;i:507-8.

2 Wyngaarden JB. The clinical investigator as an endangered species. New Engl f Med 1979;301:1254-9.

${ }^{3}$ DeGroot LJ, Siegler $M$. The morning-report syndrome and medical search. New Englf Med 1979;301:1285-7.

${ }^{4}$ Oliver MF. The shrinking base of clinical science: where are to-morrow's researchers? Eur $\mathcal{F}$ Clin Invest 1979;7:1-2. 